\title{
Exploring the Similarities Between Users and Non-Users of Consumer Mobile Internet Services:
}

\section{Towards a Porosity Model of Technology Acceptance}

\author{
Stéphanie Gauttier, Université de Nantes, Nantes, France
}

Claire Gauzente, Université de Nantes, Nantes, France

\begin{abstract}
While mobile technologies have become pervasive, some consumers remain reluctant to accept, adopt and use them. Literature traditionally opposes the notions of 'user' and 'non-user' but recent developments show the boundary between these two concepts is very thin. The aim of this article is to review theoretical frameworks that are available for understanding such consumer attitudes and behaviours and to confront theoretical analysis with in-depth subjective investigation of a non-user, occasional user and heavy user, facing a set of different mobile media offers. The empirical analysis is conducted using Q-method. Results demonstrate similarities among users and non-users when considering their attitude towards different technologies, which opens opportunities for market consumer technologies to increase their penetration rate.
\end{abstract}

\section{KEYWORDS}

Media and Technology Adoption, Non-Use, Partial Use, Q-Method, Technology Use

\section{INTRODUCTION}

In 2016, 79\% of European citizens accessed the Internet at least once a week. And yet, $45 \%$ of European citizens didn't purchase goods online. $41 \%$ didn't use the Internet on a mobile handheld device in $2016^{1}$. This means that businesses miss a significant part of the population when releasing mobile Internet services.

Yet, research on consumer use of mobile services focuses on the users, and non-users are considered in opposition to them. The reality of non-use is much more nuanced, as non-users of a specific technology can use some other technologies or make partial use of a technology. That means non-use can be understood only in relation to use, not necessarily in opposition to it. The lack of focus on the similarities between non-users and users and their motivation (not) to use prevents design services for wider audiences. Therefore, this study looks at shared representations of technologies 
between different types of (non)-users. It focuses on mobile technologies and mobile services offered to consumers, such as M-payment, augmented reality, QR-code and M-ticket.

The contribution of this research is thus threefold. First, it tries to bridge the divide in literature between users and non-users by considering the point of view of three different types of mobile technology users (non-user, occasional user, heavy user) on a set of different mobile services provided by brands or retailers. From a managerial standpoint, it allows practitioners to understand how positive and negative attitude towards different services are formed, so they can integrate consumer services to their business more effectively. Finally, it suggests that Q-method studies can document effectively the viewpoint of reluctant consumers and unveil to what extent non-use is actual, partial, arbitrary, paradoxical, and far from a binary variable.

This paper is organized in four sections. First, we review literature on use and non-use. Secondly, we present our research question and methodology. Thirdly, we present the results of the study. Finally, we discuss those results in relation to existing literature and future research.

\section{RELATED LITERATURE}

The analysis of use (1) and non-use literature (2) reveals that although literature dedicated to usage and literature dedicated to non-usage should have mirror-like logic, the underlying perspectives are indeed different. When it comes to consumer use of technology, research adopts the prism of 'use' (3). Approaches considering non-use of consumer technology are required to be able to market consumer services in a more efficient way. These approaches must consider the subjective representational space of users to explain their perception and behaviour.

\section{Literature on Use: Focus on Operational and Social Acceptation}

A user is defined in the ISO/IEC standards 2007 and 2011 (Baumer, Ames, Burrell, Brubacker, \& Dourish, 2015) as 'an individual or group who uses a software product to perform a specific function' and gets 'benefits from its utilization'.

The usage-centred studies can be split into two sub-categories identified by Brangier, HammesAdelé and Bastien (2010): the operational acceptation on one hand and the social acceptation on the other hand.

The operational acceptation of technology derives from the ergonomics where the usability, ergonomic criteria and model of interaction are at the heart of technological acceptance. However, beyond operational acceptance which is important from a design standpoint, Orlikowski and Baroudi (1991, p. 7) pointed out that researchers need to understand social processes that underlie the introduction, creation, use, misuse and abandon of ICT.

For this reason, several theoretical attempts were made in order to conceptualize technology use. One of the most prominent models is the TAM - Technology Acceptance Model, proposed by Davis $(1986,1989)$ and refined in subsequent publications. This model explains intention to use and actual use by attitude toward technology, perceived usefulness and perceived ease of use. This model is very popular and has been tested in many settings. Critiques and refinements have also emerged with time (Legris, Ingham \& Collerette, 2003; Turner, Kitchenham, Brereton, Chareters \& Budgen, 2010; Brangier et al, op. cit.). Alternative conceptualizations have also been proposed. Among the most fruitful, we can cite the Expectation-Confirmation Theory - ECT (Bhattacherjee, 2001; Bhattacherjee \& Premhumar, 2004) derived from the Satisfaction Approach (Oliver, 1980), the Task-Techno Fit Model - TTF (Cane \& McCarthy, 2009; Goodhue \& Thompson, 1995), the Structurationist approach (DeSanctis \& Poole, 1994; Orlikowski, 1992), and the Coping Model of User Adaptation (Beaudry \& Pinsonneau, 2005, 2010).

These approaches address different stages and aspects of ICT acceptance and use. The ECT model suggests that expectations toward the technology at one point in time and the satisfaction 
derived from its first use explain the decision to use technology in the future. Continued ICT use is then related to expectations and their confirmation via satisfaction and perceived value (Dai, $\mathrm{Hu}, \&$ Zhang, 2014). The TTF model holds that utilization depends on the task to be accomplished and the technological characteristics. When task requirements and technology characteristics fit, utilization and satisfaction are more liable. Fit assessment depends on the use context. In the long run, the individuals' performance in ICT use is also more likely. The structurationist approach points out that IT use, mainly in organizations, challenges theory and organizations as it induces changes. A dynamic and interactionist view is proposed and emphasizes social interactions emerging from IT adoption and use. The Coping Model of User Adaptation suggests that emotions constitute a significant part of ICT acceptation, first use and continued use. Different emotions have been studied: enjoyment, pleasure, anxiety and playfulness.

All in all, these different approaches hold a common view that technology acceptance and use is socially constructed, influenced by utilization context, and by individuals' emotions and attitudes. In line with this, IT use or non-use does not merely appear as a matter of meeting ergonomic or technical requirements. The social stance at accepting and using technology is also prevalent in the non-usage literature.

\section{Non-Use Literature: Move Towards Understanding Voluntary Non-Use}

Non-users have long been seen as individuals who do not have access to technology. Non-usage approaches include many digital divide studies such as Rice and Katz (2003) and represent a dynamic stream of research (Brandtzæg, Heim, \& Karahasanovic, 2011; Cruz-Jesus, Oliveira, \& Bacao, 2012). The most classical predictors of digital inequalities are income or socio-economic status as well as gender, age, education, and family structure. Such approaches consider that non-users have no agency over their access to technology and are involuntary non-users. And yet, other categories of non-users are emerging. They can be mapped out as 1) resisters, who never had access to a technology and never wanted it; 2) rejecters, who tried a technology but gave it up voluntarily; 3) expelled, who had access but lost it; 4) excluded, who have no access to technology but have not chosen it (Wyatt, 2003).

Research on non-use focuses on practices of non-use (Van House, 2015), but the motivations behind non-use are only little understood. HCI looks at non-use as a barrier to adoption, while nonuse is a form of use that is meaningful, motivated and directed. Van House (2015) highlights there's a light of understanding in the motivations behind non-use, as motivation-focused research is focusing on behaviour change goals (Sleeper, Acquisti, Cranor, Kelley, Munson \& Sadeh, 2015), and others look at a cost-advantages relationship (Selwyn 2003, Baumer et al 2015). One of the challenges faced by research on non-use is the difficulty for non-users to explain their behaviour beyond being 'not interested' (Van House, 2015; Lampe, Vitak, \& Ellison, 2013). Lampe et al (2013) declare that this answer is a cover for more complex concerns. Often, non-usage is looked from the perspective of the technology, in a uni-dimensional way. Approaches allowing to capture the complex relationship of non-users to technology are required. The status of non-user is not absolute. Rather, one should consider developing a continuum of types of involvement with technology considering the dynamic and multi-dimensional relationship one has with technology (Wyatt, 2014). For instance, Neves, De Matos, Rente, and Martins (2015) propose a typology with resisters, rejecters, surrogate users (using somebody else's device), and potential converts, who are considering or reconsidering technology use. Being a non-user is also relative to a specific potential or imagined use of technology (Ems, 2015). Integrating usage-centered literature, and particularly the utility concept, opens alternative interpretations of non-use (Verdegem \& Verhoest, 2009). Verdegem and Verhoest (2009) developed the ASA model, comprising Access, Skills and Attitude, in order to explain technology appropriation and thus e-inclusion or exclusion. This echoes the work by Selwyn $(2003,2006)$ who already underlined that the patterns of non-engagement in technology and media vary between technologies and feature different types of non-users. Typically, Selwyn distinguishes three reasons for non-usage: non-access 
(lack of economic, cultural or cognitive resources); technophobia and ideological refusal. Resistance to new media developments can also be explained by a combination of assemblage and affect theory (Thorén \& Kitzmann, 2015). The study by Thorén and Kitzmann show that digital technologies for music can be ignored by individuals who see their musical entertainment as an emotional and experiential activity.

Other refinements exist, for instance, Jauréguiberry (2012) focuses more precisely on voluntary non-usage where non-use is not necessarily absolute, but partial (certain usages are simply paused) and segmented (limited to certain periods of the day for instance). Ribak and Rosenthal (2015) show that this type of resistance, which they call media ambivalence, is directed at one technology and its personal meaning and societal significance evolves over time. A dichotomy between users and nonusers doesn't hold, as individuals are both users and non-users at the same time. Rather, personal motives for using specific technologies whilst avoiding others is key to understanding behaviours of use and non-use.

\section{Consumer Technology Usage: Mainly Approached Through the 'Use' Literature}

The appearance of new technologies triggers the interest of Academics to research their potentials for consumer services. For instance, the use of sms advertising (Gauzente, 2010), augmented reality (Bulearca and Tamarjan, 2010), or QR-codes (Okazaki, Navarro-Bailon, \& Milna-Castillo, 2012 b) has been investigated. This research is mainly descriptive and can be classified into three categories:

1. Studies explaining the formation of users' perception of technology and their impact on use (Gauzente, 2010, Okazaki, et al., 2012b);

2. Studies explaining attitude towards the technology, with research on the role of different variables such as ubiquity (Okazaki, Molina \& Hirose, 2012 a) or privacy, trust and satisfaction (Kim \& Lim, 2001) on attitude towards the technology;

3. Research looking at the impact of consumer technology experience on purchase (Koivumäki, 2001), brand attitude and hedonic side of shopping (Bulearca \& Tamarjan, 2010).

The focus of this research is on users. Models and approaches coming from the 'use' literature is adopted and adapted to consumer use of technology. For instance, there is a stream of literature looking more closely as to how the TAM model can be adapted to consumers, for instance by integrating trust and risk (Pavlou, 2003), or compatibility, privacy, security, normative beliefs, and self- efficacy (Vijayasarathy, 2004). Venkatesh, Thong, and Xu (2012) propose a model of consumer acceptance of technology derived from the UTAUT model (Venkatesh, Morris, Davis \& Davis., 2003). This model, UTAUT 2, considers performance expectancy, effort expectancy, social influence, facilitating conditions, hedonic motivation, price value, habit, age, gender and experience. Individual characteristics moderate the effect of other constructs on behavioural intention and technology use.

Non-users have yet to become a core focus. Some variables identified in non-use literature, such as technophobia or technology anxiety are utilized in consumer technology research and demonstrate an impact on consumer perception self-service technologies (Meuter, Ostrom, Bitner \& Roundtree, 2003). Mobilizing non-use can be beneficial to ascertain more understanding of consumer acceptance and behaviour with technology.

This analysis of prior literature shows that 1) consumer use of technology has been well documented, but non-users and their perception of consumer mobile Internet services are more scarcely discussed; 2) there is a methodological difficulty implied by capturing non-use and comparing it to forms of use; 3 ) the porosity between use and non-use appears at a conceptual level in the literature, but empirical evidence are still lacking. This research proposes to capture empirically the porosity between use and non-use. 


\section{RESEARCH QUESTION AND METHODOLOGY}

\section{Research Question}

Based on the review of related works, we can see that the binary between users and non-users doesn't seem to hold. Non-users themselves can become surrogate users or reconsider their position given circumstances. Non-usage can also be partial or stopped. We argue that the necessity of developing continuum of involvement with technologies holds for non-users and users alike, and that the porosity of use and non-use needs to be researched more closely. This porosity may be revealed by looking at different projected uses of technologies. That's why we consider various aspects of mobile Internet, as technology overall but also through different services already available to consumers such as QRcode, augmented reality, m-ticket and m-payment. Therefore, we formulate the following questions:

RQ1: What are the commonalities in occasional user's, heavy user's, and non-user's points of view on technology?

RQ2: What hinders and drives the use of services such as QR-code, augmented reality, m-ticket and m-payment?

\section{A Brief Presentation of Q-Method}

Understanding the motives behind technology use and non-use requires a user-centred approach that can account for subjective reasons (not) to use technologies, in a multidimensional manner. More specifically, one needs to design empirical research design that a) overcome the difficulties that non-users have to explain their attitude, b) consider that an individual's point of view on technology changes depending on the specific application of technology under observation, c) consider in a holistic manner the variety of variables behind use and non-use documented in prior literature.

We chose to use the Q method (see q-method.org and Brown, 1993) as a) it allows to capture the in-depth point of view of individuals from their own point of view based on the ranking of given stimuli, b) to consider a multitude of variables included in the stimuli, and c) to then identify shared views among a given sample through mathematical analysis. Using $Q$ allows to overcome the dual methodological difficulty presented by the use of the porosity between individuals' points of view on use and non-use. Q-method has been mobilized in Information Systems about 15 times (Gauzente, 2013), especially to explain perception of technology by individuals. Yet, the distinction between users and non-users has not been central to these studies.

Given the lack of popularity of Q-method in the field, we provide a description of the key concepts behind it and steps to conduct research with Q. Q-method was developed by the psychologist Stephenson $(1935 ; 1953)$ to study subjectivity. Subjectivity is conceptualized as what 'emanates from a particular vantage point' (Brown, 1993). Fundamentally, Q-method belongs to qualitative approaches. It presents affinity with phenomenology (Shinebourne \& Adams, 2007) and aims at capturing the operant subjectivity of individuals in relation to any given topic, from their own perspective.

$\mathrm{Q}$ rests on two important pillars. One is theoretical and refers to concourse theory, the other is methodological and uses Q-sorting procedure and q-factorial analysis (Gauzente; 2010). Based on these elements, the procedure to follow to set up a Q-study is as follows:

1. The first step to set up a Q-study is to create the concourse. Concourse can be defined as the volume of available statements on a topic. It 'is the common coinage of societies large and small, and is designed to cover everything from community gossip and public opinion to the esoteric discussions of scientists and philosophers' (Brown, op. cit.). Even for one individual, a single word can have several meanings, depending on circumstances and the individual's mind-set. What is important to note is that these meanings partly overlap with other people's meanings, and this is what makes interpersonal communication possible. Based on these considerations, 
Stephenson suggests that initial qualitative interviews or literature reviews should be conducted to generate as many meanings as possible concerning one topic. These meanings can be formulated as statements. Altogether, statements constitute the q-sample;

2. Then, individuals are asked to proceed to Q-sorting, i.e rank-order the statements according to the degree to which they represent their subjective view of one topic in a forced distribution matrix. The respondents are designated as the p-sample. This ranking procedure dictates that only a small portion of assertions will be selected as highly representative of one's personal vantage point, and only a small portion will be selected as badly representative; the majority will be neither representative nor non-representative (see Table 1 for a distribution of 29 statements). The result of the Q-sorting process is a q-sort;

3. Factor analysis is then used to analyse the data. This is called q-factor analysis because instead of analysing individuals, assertions or statements are analysed. A map of the representations that people have is produced, which helps to identify the different visions that people share. Factor analysis is thus used to identify underlying q-factors which correspond to shared visions. It should be emphasized that, in no way, the q-factors should be assimilated to groups of people as in typological approaches. The factors are not a statistical representation of groups in the general population. Q factors are shared views, shared interpretations of an object.

Q does not aim at generalization but at capturing existing points of view. Therefore, it can operate with small samples (McKeown \& Thomas, 2013). Stephenson (1974) has suggested single case-studies as a promising methodological possibility in order to develop in-depth knowledge of subjective issues and to unveil an individual's inner world. As he puts it, 'the non-statistical strategy leads to immediate results' (p. 3, 1974). Individual case studies allow to identify the points of view of an individual, or better yet the multitude of points of view one can have on a topic. To this extent, the Researcher aims at eliciting the respondent's point of view from different perspectives, looking at what the respondent thinks others think about the topic (Rhoads, 2015) or about different representations of the phenomena, i.e different forms of technology to apprehend the perception of mobile services (Gauzente, 2014). This results in one respondent proceeding to q-sorting several times with the same statements but changing conditions of instructions. There is no standard pertaining to the number of q-sorts needed from one respondent to proceed with a single-case. The researcher takes into account the nature of the phenomena under study, the possibility for the respondents to answer, the material generated with the respondent to create the concourse, and the level of depth and granularity deemed desirable for the study.

\section{Investigation Instrument}

For this study, the statements were selected based on a prior Q-study linked to Augmented Reality (Gauttier, Gauzente \& Aikala, 2016). The Researchers added statements in order to cover the specificities of other mobile technologies and important variables identified in the literature. For instance, the original statements did not address the notion of payment through mobile applications, so the Researchers brought them in. All in all, 29 statements were selected. They cover the different

Table 1. Q-sort statements forced distribution

\begin{tabular}{|c|c|c|c|c|c|}
\hline $\begin{array}{c}\text { Absolutely Not } \\
\text { Representative } \\
\text { of My Point of } \\
\text { View }\end{array}$ & & & $\begin{array}{c}\text { Don't Agree or } \\
\text { Disagree }\end{array}$ & $\begin{array}{c}\text { Absolutely } \\
\text { Representative } \\
\text { of My Point of } \\
\text { View }\end{array}$ \\
\hline-3 & -2 & -1 & 0 & 1 & 2 \\
\hline 2 statements & 4 statements & 5 statements & 7 statements & 5 statements & 2 statements \\
\hline
\end{tabular}


theoretical dimensions identified in both research traditions (Information Systems Research and Digital Divide/Non-Usage tradition).

Nine conditions of instruction were given, resulting in 9 Q-sorts per respondent ( $\mathrm{p}$ sample=3). The nine conditions entail the participant's a-priori view of digital media - as opposed to print - and his a-posteriori view once the different technologies and services have been presented and judged. The different technologies and services have been chosen considering several aspects:

- $\quad$ The current state of media technologies (m-ticket, QR code);

- Popularity: 'in-progress' media technologies that benefited from buzz and that most people are aware of (like google glass, augmented reality);

- The functionality of media technologies (m-ticket, m-payment);

- The fact that technologies are clearly documented online so that the participant can understand how it works.

In order to gather more social dimensions, we also include the view of what future generations or parents might think. Finally, nine conditions of instructions are retained.

The conditions of instructions are as follows:

1. What is your general viewpoint about available mobile media technologies?

2. About $\mathrm{m}$-ticket for public transportation?

3. About QR code advertising?

4. About augmented-reality product pre-visualization?

5. About Google glass?

6. About m-payments?

7. Now that we have seen several possibilities, please reassess your view of mobile services and technologies.

8. In your opinion, what would be the view of your parents?

9. In your opinion, what would be the view of future generations?

For each q-sort instrument, an example of the media technology was first given either through pictures or online video demonstrations in order to make sure that the participants understood well the media technology features and had similar representations of the different technologies under study. It is noteworthy that, as the study was done in France, the videos were showing French cases of use of the different technologies. All these technologies were widely available at the time of the study in France, with Google Glasses being an exception.

Three persons participated to the study, creating at first three single-case studies, which were then included to form one dataset.

Participants were selected based on their reported use of mobile Internet and technologies. They were asked whether they see themselves as heavy, occasional or non-user during the screening stage. Their self-qualification was further checked with the questionnaire preceding the first q-sort, in which participants were asked to characterize their relationship to technology, to their mobile phones, and rate their attitude to mobile technologies on a scale from 1 (absolutely negative) to 5 (absolutely positive). The sample constitutes of:

- A non-user of mobile Internet, who declares not having access to mobile Internet at all on her phone and is negative towards technologies overall (2). Her non-use of mobile Internet is voluntary. The respondent was not able to characterize her relationship further prior to the study;

- An occasional user, who declares about technologies that 'I just need a computer to check emails, search for weather or addresses, and check social networks (only Facebook). Surfing the 
web with other technologies, like my phone or my tablet, happens occasionally, like when I'm waiting or when I spend a couple of days out of home...'. This participant appears as a partial user, partial non-user;

- A heavy user, who declares mobile Internet is part of his daily life and he could 'hardly do without it now'. This participant's usage of mobile Internet is wide, as many applications are reported being used, from social networks to online purchases. He is highly favorable to technology (4).

A summary of participant characteristics is provided in Table 2.

The participants proceeded to the q-sorts in their daily environment. The Researchers explained to the participants the procedure face-to-face and were present as the participants did the first q-sorting. This ensured that the participants understood the exercise and completed it appropriately, so they could feel comfortable when proceeding to the remaining q-sorts. They were asked to proceed to 2 q-sorts per week, so that data collection lasted around 5 weeks. There were several reasons for this. First, proceeding to all 9 q-sorts over a short period of time would have decreased the quality of the data we gathered: participants would not have had time to fully consider each technology on its own and could have been tired of the exercise. Second, long durations of studies are often a barrier for participants. 5 weeks appeared to be sufficient for the Researchers and rather easy to accept for participants.

During the first Q-sorting procedure, no comments were made on the statements, suggesting that they were deemed exhaustive across the sample.

Finally, q-factor analysis was run on all 27 Q-sorts altogether (3 times 9 Q-sorts) on the PQ method software. The results reveal five q-factors. Some of them are relative to one user, while some express shared views. Table 3 summarizes the characteristics of the second-order factors.

\section{RESULTS}

The five views we observe from the five synthetic Q-sorts are described below. The description of each view stems from the data obtained as a result of the factorial analysis. Indeed, not only does the analysis identify shared views, it also provides the z-score of each statement for that given view so that it is possible to see how the point of view is structured and analyse the role of the different

Table 2. Participant characteristics

\begin{tabular}{|c|c|c|c|}
\hline & Non-User & Occasional User & Heavy User \\
\hline Gender & $\mathrm{F}$ & $\mathrm{F}$ & M \\
\hline Age & 32 & 26 & 35 \\
\hline Smartphone & Yes & Yes (2 years) & Yes (4 years) \\
\hline Mobile Internet & No & Yes (Social networks) & Yes \\
\hline Online purchase & No & No & Yes (up to $300 €$ ) \\
\hline $\begin{array}{l}\text { Attitude to mobile } \\
\text { technologies ( } 1= \\
\text { Absolutely negative, } 5= \\
\text { absolutely positive) }\end{array}$ & 2 & 3 & 4 \\
\hline Role of mobile phone & Purely functional & Purely Functional & Very convenient \\
\hline Relationship to technology & & $\begin{array}{l}\text { Mobile Internet in specific } \\
\text { circumstances - waiting } \\
\text { or away }\end{array}$ & Part of daily life. \\
\hline
\end{tabular}


Table 3. Comparative Q-factors characteristics

\begin{tabular}{|l|l|l|l|l|l|}
\hline \multicolumn{1}{|c|}{$\mathbf{2}^{\text {nd }}$ Order Q-Factor } & \multicolumn{1}{|c|}{ View \#1 } & \multicolumn{1}{c|}{ View \#2 } & \multicolumn{1}{c|}{ View \#3 } & \multicolumn{1}{c|}{ View \#4 } & \multicolumn{1}{c|}{ View \#5 } \\
\hline Involved q-sort & $\begin{array}{l}\text { NU general, NU } \\
\text { m-ticket, NU } \\
\text { QRcode, NU } \\
\text { AR, NU Google } \\
\text { glasses, NU } \\
\text { M-payment, NU } \\
\text { ex-post }\end{array}$ & $\begin{array}{l}\text { OU } \\
\text { previsualisation, } \\
\text { OU future, NU } \\
\text { future, HU } \\
\text { m-ticket, HU } \\
\text { previsualisation, } \\
\text { HU future }\end{array}$ & $\begin{array}{l}\text { OU parents, HU } \\
\text { google glass, } \\
\text { HU m-payment, } \\
\text { HU expost, HU } \\
\text { parents }\end{array}$ & $\begin{array}{l}\text { OU general, OU } \\
\text { google glasses, } \\
\text { HU QRcode }\end{array}$ & OU m-payment \\
\hline $\begin{array}{l}\% \text { of explained variance } \\
\text { (Total =79\%) }\end{array}$ & 25 & 18 & 17 & 11 & 8 \\
\hline
\end{tabular}

Note: NU means Non-User, OU means Occasional User, HU means Heavy user

items. Then, the researchers have access to tables presenting areas of differences and consensus across the factors.

Data analysis is made in two steps. Firstly, the researchers analyse one factor after the other, looking at its structure. The statements z-score are used to produce a synthetic q-sort for the view. The Researchers write a summary for each view guided by the statements that are most agreed and disagreed with. Secondly, the researchers do a comparative analysis of the factors between each other using the data on areas of consensus and differences. This allows to revise the summaries to make sure that key distinguishing factors for each sort are present in the description, increasing the granularity of the analysis. It allows to present a comparative summary.

We provide a summary for each factor separately and then propose a cross-factorial discussion. In the descriptions below, the numbers in parenthesis after the quotations denote the ranking of the corresponding statement in the synthetic sort for each view.

All data concerning the five factors, the synthetic sorts, and the list of statements used in this study can be accessed upon request to the authors.

\section{View 1: Distanced View}

The first view identified is a distanced view. It is defined by several Q-sorts from the non-user (general, m-ticket, QR code, augmented reality, google glasses, m-payment, ex-post) and explains $25 \%$ of variance.

This point of view expresses a lack of interest for mobile, as our non-user is not 'fond of' these technologies $(+3)$ and she doesn't want to try them $(+2)$. Technologies are not seen as dangerous $(-2)$, but they are not pleasant either $(-2)$, nor exciting $(-3)$. This view shows a lack of an emotional connection to mobile technologies. It adds up to a perceived lack of functionality for this particular user as technologies are 'not vital, I don't really need it', even though they are 'coherent with our more and more mobile way of life' $(+2)$. There is ideological reason not to use technologies, no fear linked to security or privacy, but a lack of need for these mobile technologies. This suggests people with distanced views such as this non-user might come to using technologies depending on circumstances, when they have a rational reason for it.

\section{View 2: Enthusiastic View}

The second view identified in the factor analysis is a more enthusiastic view. The most representative Q-sorts defining this view are some of the occasional user (previsualisation, future), of the heavy user (previsualisation, future) and of the non-user (future). It is interesting to note that all respondents share similar representations of technologies as seen by future generations, and that this point of view is a positive one.

Indeed, this point of view depicts technologies as very convenient and practical: they make life easier $(+3)$ and allow to make purchases from anywhere $(+3)$. They are seen as modern $(+2)$, and 
one would 'want to try' $(+2)$. In this enthusiastic view, no real danger is linked to technology. One can understand how they work.

\section{View 3: Critical View}

The third view is rather pessimistic, although it is defined mainly by Q-sorts from the heavy user of our sample (google glasses, m-payment, ex-post, parents) and one q-sort from the occasional user (parents). This shows that users can be more reluctant towards one technology than the other, and be at times non-users.

This point of view highlights a lack of trust in mobile technologies, and a fear one might become dependent on them $(+3)$. There are risks associated to payment security $(+3)$. Technology are dangerous $(+2)$, and synonymous with advertising $(+2)$.

Overall, people sharing this point of view are not fond of technologies $(+2)$. This might be linked to the lack of positive hedonic experience perceived by participants: this view sees mobile technologies as not playful, not exciting (-3), and not pleasant (-3).

\section{View 4: Need-Fulfilment Focused View}

The fourth view uncovered by the analysis is also a critical one. It is defined by Q-sorts from the occasional user (general, google glasses) and the heavy user (QR-code). In this view, mobile technologies imply a risk of dependency $(+3)$ and are not vital $(+3)$. People sharing this point of view do not want to try technologies and are not fond of them $(+2)$, even though they understand them.

This point of view is rather negative, but doesn't entail the distrust and danger seen in the third view. Here, statements like 'These technologies are dangerous' are negatively rated (-2), while they appeared positively rated in the previous view $(+2)$. The main driver of this point of view seems to be the lack of need for technology. It is somehow close to view 1, except that in view 4 participants claim they understand how technologies work, and are neutral when it comes to linking them and lifestyle. This fourth point of view represents an opinion on specific technologies (QR-code, Google Glasses), which appear as not vital to respondents. It is also composed of the q-sort on the occasional user's general point of view of technologies. They would be overall unnecessary, and yet used in particular instances.

\section{View 5: Security-Centered View}

The last point of view identified is specific to the view on m-payment of the occasional user and expresses security concerns. This view is the only one centered around perceived risks linked to data-protection and security of payment $(+3)$. It is seen as dangerous $(+2)$ and good only to draw attention $(+2)$.

M-payment is not exciting (-3), not playful and the user expressing this point of view wouldn't try it even if [she] wouldn't have a minute to go to the store. Rejection is driven by a high level of risks associated to technology.

\section{Consensus and Disagreement on Statements Among Points of Views}

Even though the analysis allows to identify different points of view and explain each of them independently, it also provides understanding in terms of consensus and differences across the views.

The most consensual statements refer to the possibility for 'brands and companies to be closer to consumers', human contact, questions linked to tariffs plan and making information more accessible. These statements are all neutrally ranked in all 5 views, indicating they're taken for granted.

Some statements are almost homogenously ranked across views. It appears that all points of view share a negative ranking of 'These technologies are exciting!' (-3), 'I am curious to try' (-2 and -3), 'pleasant to use' (-2 and -1), 'playful and fun' (-1 and -3) except for the second, enthusiastic view. Emotional connection seems to be one of the main difference between enthusiastic perception of 
technologies - which was formed mainly by heavy user's Q-sorts, some of the occasional user, and only the future like representation of the non-user - and more prudent views.

As far as the utilitarian dimension is concerned, one should note that the critical view (view 3 ) can be distinguished from the others by the neutral ranking of 'it's not practical', while all other points of view show a negative attitude to this statement. But perceived utility seems to be explaining more the behaviour appearing in rejecting and prudent views, for which 'it's not necessary, I don't need it' is positively rated ( +3 for view 1 and $4 ;+1$ for views 3 and 5).

Ideology doesn't seem to be driving non-use and use, as the statement linked to human factor and the need for face to face interaction appeared rather neutral among all points of view, with this statement ranked as 0 or +1 . Besides, only the enthusiastic view disagrees that 'it's better to go the store than live behind one's screen' (-2), while in other points of view this statement is rated +1 .

Only the enthusiastic view and the rejecting view (around the non-user's q-sort) are positive that technologies are 'the future', while others are neutral. This points at the possibility for the non-user to reconsider her position at another point in time.

\section{DISCUSSION}

The first purpose of this study was to identify whether there were commonalities between the points of view of non-user, occasional user and heavy user on mobile technologies. By looking at the phenomena of use and non-use from a user's perspective and capturing different dimensions of attitude towards technology, this study shows that the boundary between heavy user, occasional user and non-user is porous.

Indeed, with the exception of views 1 and 5, all views in our sample are constituted by Q-sorts from two to three types of users. The analysis of consensual statements among views also shows that variables can be rated the same, implying that the three users share the same point of view on such constructs as access to information, access to technology and tariff plans, or the need for human contact. Some other constructs are not homogenous across all points of views, but almost. They refer to the shared meaning of the occasional and heavy user, non-user and heavy-user, and non-user and occasional user.

Porosity also works in terms of the identity and behaviour displayed by users and non-users. As indicated in Neves et al (2015), non-users can be seen as potential converts. In our study, the nonuser's view of future and technology is as enthusiastic as the one of the heavy user today, which may indicate a possible reconsideration of attitude with time.

When considering particular technologies, one can see that the heavy user is close to the occasional user's views (of other technologies), as it is the case for the heavy user's sort on QR code, which creates view 4 together with the occasional user's general q-sort and q-sort on google glasses. The point of view of the heavy user appears in three views, drawing on sorts on different technologies, indicating a multi-dimensional relationship to technology within this user, and different degrees of closeness to other types of users. The degree of involvement must be looked at for different applications of a technology, as here mobile Internet was illustrated with 5 specific examples of use. Furthermore, the non-user's rejecting point of view described in view 1 appears to be driven more by a lack of perceived utility for her circumstances than an ideological resistance, suggesting possibilities for acceptance of mobile technologies in different circumstances. There is a negotiation, some bricolage and assemblage between ideological motives (risk of dependency), security- and privacy-related risks to be taken, convenience to be gained, in all situations.

Therefore, the idea of looking at use and non-use as at continuum of engagement with technology (Wyatt, 2014) seems valid, pushing towards a porosity model of technology acceptance. Our study allows to document motivations behind non-use, partial non-use, partial use and use (see Figure 1).

Non-use, voluntary or not, is the absence of technology usage. The first view identified in this study corresponds to the non-user's Q-sorts and shows lack of interest for technology, explaining 
voluntary non-use. The fifth view, based on the occasional user's q-sort on m-payment shows rejection of technology for security concerns, and can be attached to non-use. It is in line with the self-declared non-use of m-payment by the participant. Partial non-use describes the intentional nonuse of a technology in specific setting or period of time. It stems from a reflexive, critical approach. This approach was identified in view 3, based on some of the heavy user's and occasional users' Q-sorts, and shows that risks linked to technology use can overcome the otherwise positive attitude of participants to technology. Perceived risks can lead to partial non-use of technology, or voluntary non-use. Partial use is characterized by the use of a technology in a specific setting or period of time, which corresponds to the occasional user of our study, who uses mobile internet technologies in specific circumstances such as being away for a couple of days or waiting somewhere. Partial use can be driven by the need to fulfil concrete needs, as identified in view 4 . Use refers to views accepting technology, and in which one wants to try it. In this study, it is visible in view 2 , which is structured around positive perception of both functional and hedonic aspects of technology. Notions of frequency of use could be documented in further research (daily use, moderate use, etc). In this study, they were self-declared and based on general use of technology, not of specific services. That level of granularity could be documented in further research, so as to highlight motives for prolonged use and loyalty to technology consumer services.

Besides highlighting the artificiality of the binary use/non-use, this study provides insights in terms of variables explaining use and non-use and shows how new method can help document the phenomenon. This study confirms the relevance of certain constructs in explaining technology use and non-use, such as the hedonic aspect (Venkatesh et al., 2012; Beaudry \& Pinsonneau, 2005, 2010), which appeared strongly in all views somewhat accepting technologies. The notion of context and facilitating conditions (Venkatesh et al., 2012; Goodhue \& Thompson, 1995) is also structuring views, as the non-user seems not to identify moments or tasks technology could help her with (view 4).

Second, from a managerial standpoint, this study speaks to the motivations behind use/non-use, which can be utilized to support conversion of potential users. Indeed, looking at the continuum obtained (Figure 1), one can see how participants are both (partial) non-users and (partial users). This means that by addressing security issues (view 5) and highlighting functional aspects of technology (view 4), the penetration of consumer technology usage could be increased. The results of this study also show that not all consumer mobile services are perceived in the same way as they present

Figure 1. A continuum of non-use and use, illustrated with the 3 cases presented in this study: A porosity model of use / non-use

\begin{tabular}{|c|c|c|c|}
\hline \multicolumn{2}{|c|}{ Points of view centered on Non-use } & \multicolumn{2}{|c|}{ Points of view centered on Use } \\
\hline Non-use & $\begin{array}{l}\text { Partial } \\
\text { Non-use }\end{array}$ & $\begin{array}{l}\text { Partial } \\
\text { Use }\end{array}$ & Use \\
\hline $\begin{array}{l}\text { View } 1 \text { - Distanced View } \\
\text { (lack of interest) } \\
\text { NU General, M.ticket, QR } \\
\text { code, AR, Google Glasses, M- } \\
\text { payment, Ex-p̧ost }\end{array}$ & & $\begin{array}{l}\text { View } 4 \text { - Need-fulfilment } \\
\text { focused view } \\
\text { OU General, Google Glasses, } \\
\text { IUU QR.code }\end{array}$ & $\begin{array}{l}\text { View } 2 \text { - Enthusiastic siew } \\
\text { OU Previsualisation, OU Future, } \\
\text { NU Future, HU M-ticket, HU } \\
\text { Previsualietion, HU Future }\end{array}$ \\
\hline \multicolumn{4}{|l|}{$\begin{array}{l}\text { View 5. Security-centered } \\
\text { view } \\
\text { OU M-payment }\end{array}$} \\
\hline $\begin{array}{l}\text { View } 3 \text { - Critical approach (tr } \\
\text { OU Parents, HU Google Glass, } \\
\text { parents }\end{array}$ & yment, HU ex-post, HU & & \\
\hline
\end{tabular}


different pros and cons for different types of users. M-payment appears in three different views (1; 3 and 5), which are rejecting or ambivalent views, where non-use is driven by critical considerations or security concerns. This perception is far from the enthusiastic view of users on previsualisation, future technologies or even m-ticket, which is driven by both hedonic motivation and functional relevance. To spread this technology, security concerns must be addressed, and it must be made clear to consumers how this technology can help them (echoing view 4, but also view 1 in which the non-user doesn't feel the need for these technologies). The wow-effect often associated with new technology doesn't appear as a driver on the continuum of use and non-use. This also means that when preparing the launch of new consumer technologies, marketers should involve not only people who are generally favourable to technology, but also individuals presenting more prudent profiles. This would allow to identify scenarios of use, barriers, and design communications addressing them, so as to guarantee a higher penetration rate for the services launched.

Finally, $\mathrm{Q}$ is used to tackle challenges identified by literature. Previous work points to the difficulty of non-users explaining their behaviour beyond a declaration of use and non-use (Van House, 2015). Approaches involving data triangulation are required, as well as approaches that allow participants to express their points of view by reacting to specific stimuli. Besides, research on non-users focuses on practices of non-use (Ems, 2015), but the motivations behind non-use are not explained much. Q-method provided a tool for the non-user to be able to express her point of view in an articulated way so as to identify operant factors, that guide participants' behaviours. The use of $\mathrm{Q}$ also allowed to compare the points of view of different users in a structured way so that qualitative comparative analysis could be carried. Further developments could attempt at measuring the different variables at stake and offer comparative analysis on larger samples. The latter would allow to weight in the role of gender, habits and other individual characteristics that have been identified as moderating the impact of hedonic and functional variables. Splitting users into partial users, moderate users and intensive users could allow to gain a more nuanced understanding of motivations behind use as well.

\section{CONCLUSION}

Users and non-users of consumer mobile services share common representations. They can all be critical at times; when they are not sure of the functional role of the service considered, or when other structural issues are at stake (privacy, data protection). They can also be enthusiastic about technologies as they are now or how they will be in the future, highlighting both growing demands towards technology and a potential increase in users of these services. Their points of view are defined in relationship to specific technologies. And even the non-user's rejecting point of view shows there is room for change if only technology could fill in a need. Looking at the continuum of users and non-users is thus relevant given the porosity between the two groups, especially when designing new technologies and evaluating them. Indeed, by understanding shared representations, one can design and communicate new technologies in a way to convert non-users in potential users. 


\section{REFERENCES}

Baumer, E. P., Adams, P., Khovanskaya, V. D., Liao, T. C., Smith, M. E., Schwanda Sosik, V., \& Williams, K. (2013). Limiting, leaving, and (re) lapsing: an exploration of facebook non-use practices and experiences. In Proceedings of the SIGCHI conference on human factors in computing systems (pp. 3257-3266). ACM. doi:10.1145/2470654.2466446

Beaudry, A., \& Pinsonneault, A. (2005). Understanding User Responses to Information Technology: A Coping Model of User Adaptation. Management Information Systems Quarterly, 29(3), 493-524. doi:10.2307/25148693

Beaudry, A., \& Pinsonneault, A. (2010). The Other Side of Acceptance: Studying the Direct and Indirect Effects of Emotions on Information Technology Use. Management Information Systems Quarterly, 34(4), 689-710. doi:10.2307/25750701

Bhattacherjee, A. (2001). Understanding Information Systems Continuance: An Expectation-Confirmation Model. Management Information Systems Quarterly, 25(3), 351. doi:10.2307/3250921

Bhattacherjee, A., \& Premkumar, G. (2004). Understanding changes in belief and attitude toward information technology usage: A theoretical model and longitudinal test. Management Information Systems Quarterly, 28(2), 229-254. doi:10.2307/25148634

Brandtzæg, P. B., Heim, J., \& Karahasanović, A. (2011). Understanding the new digital divide-A typology of Internet users in Europe. International Journal of Human-Computer Studies, 69(3), 123-138. doi:10.1016/j. ijhcs.2010.11.004

Brangier, E., Hammes-Adelé, S., \& Bastien, J. (2010). Analyse critique des approches de l'acceptation des technologies: De l'utilisabilité à la symbiose humain-technologie-organisation. Revue Européenne de Psychologie Appliquée, 60(2), 129-146. doi:10.1016/j.erap.2009.11.002

Brown, S. P. (1993). A Q methodological tutorial. Operant Subjectivity, 16, 91-138. Retrieved October 3, 2005, from www.qmethod.org

Bulearca, M., \& Tamarjan, D. (2010). Augmented reality: A sustainable marketing tool. Global Business and Management Research: An International Journal, 2 (2 \& 3), 237-252.

Cane, S., \& McCarthy, R. (2009). Analyzing the factors that affect information systems use: A task-technology fit meta-analysis. Journal of Computer Information Systems, 50(1), 108-123.

Cruz-Jesus, F., Oliveira, T., \& Bacao, F. (2012). Digital divide across the European Union. Information \& Management, 49(6), 278-291. doi:10.1016/j.im.2012.09.003

Dai, H., Hu, T., \& Zhang, X. (2014). Continued Use of Mobile Technology Mediated Services: A Value Perspective. Journal of Computer Information Systems, 54(2), 99-109. doi:10.1080/08874417.2014.11645690

Davis, F. D. Jr. (1986). A technology acceptance model for empirically testing new end-user information systems: Theory and results. Massachusetts Institute of Technology.

Davis, F. D., Bagozzi, R. P., \& Warshaw, P. R. (1989). User acceptance of computer technology: A comparison of two theoretical models. Management Science, 35(8), 982-1003. doi:10.1287/mnsc.35.8.982

DeSanctis, G., \& Poole, M. S. (1994). Capturing the complexity in advanced technology use: Adaptive structuration theory. Organization Science, 5(2), 121-147. doi:10.1287/orsc.5.2.121

Ems, L. (2015). Exploring ethnographic techniques for ICT non-use research: An Amish case study. First Monday, 20(11). doi:10.5210/fm.v20i11.6312

Gauttier, S., Gauzente, C., \& Aikala, M. (2016). Are AR shopping services valued the same way throughout Europe? A four-country Q-investigation. Systèmes d'information \& management, 21(1), 69-102.

Gauzente, C. (2010). Does Anybody Read SMS-Advertising?: A Qualitative and Quantitative Study of Mobile Users' Attitudes and Perceived Ad-Clutter. International Journal of Technology and Human Interaction, 6(2), 13-29. doi:10.4018/jthi.2010040102

Gauzente C. (2014). Digging into the Subjectivity of Mobile App's Non-Users - A Single-Case Study Approach. Operant Subjectivity, 37(4). 
Goodhue, D. L., \& Thompson, R. L. (1995). Task-technology fit and individual performance. Management Information Systems Quarterly, 19(2), 213-236. doi:10.2307/249689

Jauréguiberry, F. (2012). Retour sur les théories du non-usage des technologies de communication. In S. Proulx \& A. Klein (Eds.), Connexions: communication numérique et lieu social (pp. 335-350). Namur: Presses universitaires de Namurn.

Kim, S. Y., \& Lim, Y. J. (2001). Consumers' perceived importance of and satisfaction with internet shopping. Electronic Markets, 11(3), 148-154. doi:10.1080/101967801681007988

Koivumäki, T. (2001). Customer satisfaction and purchasing behaviour in a web-based shopping environment. Electronic Markets, 11(3), 186-192. doi:10.1080/101967801681008022

Legris, P., Ingham, J., \& Collerette, P. (2003). Why do people use information technology? A critical review of the technology acceptance model. Information \& Management, 40(3), 191-204. doi:10.1016/S0378-7206(01)00143-4

McKeown, B., \& Thomas, D. B. (2013). Q methodology (Vol. 66). Sage publications.

Meuter, M. L., Ostrom, A. L., Bitner, M. J., \& Roundtree, R. (2003). The influence of technology anxiety on consumer use and experiences with self-service technologies. Journal of Business Research, 56(11), 899-906. doi:10.1016/S0148-2963(01)00276-4

Neves, B. B., de Matos, J. M., Rente, R., \& Martins, S. L. (2015). The 'Non-aligned' Young People's Narratives of Rejection of Social Networking Sites. Young, 23(2), 116-135. doi:10.1177/1103308815569393

Okazaki, S., Molina, F. J., \& Hirose, M. (2012 a). Mobile advertising avoidance: Exploring the role of ubiquity. Electronic Markets, 22(3), 169-183. doi:10.1007/s12525-012-0087-1

Okazaki, S., Navarro-Bailón, M. Á., \& Molina-Castillo, F. J. (2012 b). Privacy concerns in Quick Response code mobile promotion: The role of social anxiety and situational involvement. International Journal of Electronic Commerce, 16(4), 91-120. doi:10.2753/JEC1086-4415160404

Oliver, R. L. (1980). A cognitive model of the antecedents and consequences of satisfaction decisions. JMR, Journal of Marketing Research, 17(4), 460-469. doi:10.2307/3150499

Orlikowski, W. J. (1992). The duality of technology: Rethinking the concept of technology in organizations. Organization Science, 3(3), 398-427. doi:10.1287/orsc.3.3.398

Orlikowski, W. J., \& Baroudi, J. J. (1991). Studying information technology in organizations: Research approaches and assumptions. Information Systems Research, 2(1), 1-28. doi:10.1287/isre.2.1.1

Pavlou, P. A. (2003). Consumer acceptance of electronic commerce: Integrating trust and risk with the technology acceptance model. International Journal of Electronic Commerce, 7(3), 101-134.

Rhoads, J. (2015). Science and the single-case: the political view of Cole, an "administrator. In Proceedings of the 31st conference of the International Society for the Scientific Study of Subjectivity, Ancona.

Ribak, R., \& Rosenthal, M. (2015). Smartphone Resistance as Media Ambivalence. First Monday, 20(11). doi:10.5210/fm.v20i11.6307

Rice, R. E., \& Katz, J. E. (2003). Comparing internet and mobile phone usage: Digital divides of usage, adoption, and dropouts. Telecommunications Policy, 27(8), 597-623. doi:10.1016/S0308-5961(03)00068-5

Satchell, C., \& Dourish, P. (2009). Beyond the user: use and non-use in HCI. In Proceedings of the 21st Annual Conference of the Australian Computer-Human Interaction Special Interest Group: Design: Open 24/7 (pp. 9-16). ACM. doi:10.1145/1738826.1738829

Selwyn, N. (2003). Apart from technology: Understanding people's non-use of information and communication technologies in everyday life. Technology in society, 25(1), 99-116. doi:10.1016/S0160-791X(02)00062-3

Selwyn, N. (2006). Digital division or digital decision? A study of non-users and low-users of computers. Poetics, 34(4), 273-292. doi:10.1016/j.poetic.2006.05.003

Shinebourne, P., \& Adams, M. (2007). Q-methodology as a phenomenological research method. Existential Analysis, 18(1), 103. 
Sleeper, M., Acquisti, A., Cranor, L. F., Kelley, P. G., Munson, S. A., \& Sadeh, N. (2015). I Would Like To..., I Shouldn't..., I Wish I...: Exploring Behavior-Change Goals for Social Networking Sites. In Proceedings of the 18th ACM Conference on Computer Supported Cooperative Work \& Social Computing (pp. 1058-1069). ACM. doi:10.1145/2675133.2675193

Soopramanien, D. G., \& Robertson, A. (2007). Adoption and usage of online shopping: An empirical analysis of the characteristics of 'buyers' 'browsers' and 'non-internet shoppers'. Journal of Retailing and Consumer Services, 14(1), 73-82. doi:10.1016/j.jretconser.2006.04.002

Stephenson, W. (1935). Correlating Persons instead of Tests. Character and Personality, 4(1), 17-24. doi:10.1111/j.1467-6494.1935.tb02022.x

Stephenson, W. (1953). The study of behavior: Q-technique and its methodology. Chicago: University of Chicago Press.

Stephenson, W. (1974). Methodology of single case studies. Journal of Operational Psychiatry.

Thorén, C., \& Kitzmann, A. (2015). Replicants, imposters and the real deal: Issues of non-use and technology resistance in vintage and software instruments. First Monday, 20(11). doi:10.5210/fm.v20i11.6302

Turner, M., Kitchenham, B., Brereton, P., Charters, S., \& Budgen, D. (2010). Does the technology acceptance model predict actual use? A systematic literature review. Information and Software Technology, 52(5), 463-479. doi:10.1016/j.infsof.2009.11.005

Van House, N. A. (2015). Entangled with technology: Engagement with Facebook among the young old. First Monday, 20(11).

Venkatesh, V., Morris, M. G., Davis, G. B., \& Davis, F. D. (2003). User acceptance of information technology: Toward a unified view. Management Information Systems Quarterly, 27(3), 425-478. doi:10.2307/30036540

Venkatesh, V., Thong, J. Y., \& Xu, X. (2012). Consumer acceptance and use of information technology: Extending the unified theory of acceptance and use of technology. Management Information Systems Quarterly, 36(1), $157-178$.

Verdegem, P., \& Verhoest, P. (2009). Profiling the non-user: Rethinking policy initiatives stimulating ICT acceptance. Telecommunications Policy, 33(10), 642-652. doi:10.1016/j.telpol.2009.08.009

Vijayasarathy, L. R. (2004). Predicting consumer intentions to use on-line shopping: The case for an augmented technology acceptance model. Information \& Management, 41(6), 747-762. doi:10.1016/j.im.2003.08.011

Wiredu, G. O. (2007). User appropriation of mobile technologies: Motives, conditions and design properties. Information and Organization, 17(2), 110-129. doi:10.1016/j.infoandorg.2007.03.002

Wyatt, S. (2003). Non-users also matter: The construction of users and non-users of the Internet. In N. Oudshoorn \& T. Pinch (Eds.), How users matter: The co-construction of users and technology (pp. 67-79). Cambridge, Mass.: MIT Press.

Wyatt, S. (2014). 'Bringing users and non-users into being across methods and disciplines,' CHI 2014. Toronto: Workshop Considering Why We Should Study Technology Non-use.

Wyatt, S., Thomas, G., \& Terranova, T. (2002). They came, they surfed, they went back to the beach: Conceptualizing use and non-use of the Internet. In S. Woolgar (Ed.), Virtual society? Technology, cyberbole, reality (pp. 23-40). Oxford: Oxford University Press.

\section{ENDNOTES}

http://ec.europa.eu/eurostat/web/digital-economy-and-society/data/main-tables 
Stéphanie Gauttier (stephanie.gauttier@etu.univ-nantes.fr) is a PhD candidate at the University of Nantes, France, and a Marie Curie Fellow at Trinity College Dublin, Ireland. Her research focuses on consumer perception and use of new technologies such as augmented reality.

Claire Gauzente (Claire.gauzente@univ-nantes.fr) is Professor in Management \& Social Sciences at the University of Nantes, France, and Adjunct Director of LEMNA Research Lab. Her research interests encompass perception and use of ICT. 